\title{
An Assessment of the Undergraduates' Participation in the Online Discussion Forum
}

\author{
Tella, Adeyinka, PhD \\ University of llorin. Nigeria \\ tellayinkaedu@yahoo.com
}

\author{
Adu, Emmanuel Olusola, PhD \\ University of Fort Hare. South Africa \\ eadu@ufh.ac.za
}

\section{Doi:10.5901/mjss.2014.v5n7p333}

\begin{abstract}
The paper examined the undergraduates' participation in the online discussion forum at the University of Ilorin, Nigeria. A total of 195 undergraduate students purposively selected from the Faculty of Communication and Information Sciences constituted the sample of the study. Through a survey design, questionnaire was administered to gather data from the respondents. Four research questions were developed and answered by the study. The results indicated that majority of the respondents are participating in the online forum and they are dully committed to it. Four prominent pattern of participation were identified. These are Socratic questioning, sharing of personal opinion and experiences, brainstorming and reaction posting. Similarly, considerable number of respondents usually read and responds to all posts received. The results confirmed encouragement of intellectual support in terms of sharing of knowledge and ideas between participants as part of the most common benefits. Incessant power outage and time factor based on tight schedule were identified as part of the problems participants encounter in the online forum. To improve students' participation in the online forum, the University authority should provide enough free Internet facilities/ outlets within the university community just as it is done in developed countries and some part of Africa especially South Africa.
\end{abstract}

Keywords: Online discussion forum; electronic discussion; online learning; online participation; Content contribution; Undergraduate students; University of Ilorin.

\section{Introduction}

Online discussion is defined as the process where learners and educators are actively engaged in on-line text-based communication with each other $(\mathrm{Ho}, 2002)$. Effective participation occurs where such on-line communication facilitates, amongst learners: the development of a deep understanding of the material through sharing, and critically evaluating one's own and others' ideas. Understanding how students participate in an online course is the first step to determine how best to engage students. According to Zuckerman, Blau and Monroy-Hernandez (2009), online participation and content contribution are pillars of the Internet revolution and are core activities for younger generations online. Similarly, Blau, Mor and Nuethal (2009) pointed out that online learning environments based on student-instructor and studentstudent interactions are widely used in higher education. Active online student interaction is a significant predictor of perceived learning (Rovai and Barnum, 2003), learning outcomes, and student satisfaction (Brady, 2004). Interactivity is defined as "a process-related variable concerning responsiveness" (Rafaeli and Ariel, 2008:84). Research has indicates that "with effective e-learning technologies we can create active, engaged, collaborative, and inquiry-based learning opportunities" (Wishart and Guy, 2009:142).

Consequent on the above, the issue of students' participation in the online discussion forum is being taking very seriously in the Faculty of Communication and Information Sciences, University of Ilorin, Nigeria; and effort is currently being put in place to enforce it. Part of these efforts includes the regulation that: each student's participation in the forum attracts 5\% of the overall score in the examination and that each student should have a laptop beginning from 2010/2011 session. The faculty wishes to know whether this effort is yielding a positive result in terms of facilitating learning, deepen students' knowledge in their courses and promoting information literacy skills of the students in the faculty.

Generally, studies on undergraduates' participation in the online discussion forum in the Nigeria university context are lacking. Specifically, studies on participation of students in the online discussion forum in the context of the University 
of Ilorin are also currently lacking. In the light of this, this study is considered significant in view of the fact that its' outcomes will help bridge the already identified gaps thereby making literature available on the subject matter from the population of Nigeria undergraduate students. Additional justification for this study is based on Virk (2004) recommendation that there is still much more to learn about students' online discussion practices and that studies similar to his own will be beneficial to facilitators who are looking to improve student engagement in their online courses. It is hoped that the outcomes from the study will provide a framework for improving the faculty information literacy programme and specifically students' participation in the discussion forum as a way of improving the students' information literacy skills.

\section{Literature Review}

\subsection{Learner participation in online discussion}

According to Ho (2002), participation within on-line discussions is defined as the process where learners and educators are actively engaged in on-line text-based communication with each other. Effective participation occurs where such online communication facilitates, amongst learners, the development of a deep understanding of the material through sharing and critically evaluating one's own and others' ideas, and where connections are made within elements of the learning material or with independently sourced material (justified through research and analysis). Within the scope of this paper, on-line participation will be analysed in the context of Internet based discussions within internet-based learning environments only.

Learner participation has been discussed widely as a key part of online learning. It has been conceptualized differently in several studies. For example, Hrastinski (2008) mentioned six different ways of conceptualization: accessing e-learning environments, writing, quality writing, writing and reading, actual and perceived writing and taking part and joining in a dialogue. After analysing several related studies in the literature, Hrastinski (2008:1761) proposed following definition of online learner participation: "Online learner participation is a process of learning by taking part and maintaining relations with others". It is a complex process comprising doing, communicating, thinking, feeling and belonging, which occurs both online and offline. Learner participation measuring interaction with peers and teachers in online environments can enhance learning outcomes. Researchers expressed that participation positively affect learning, quality assessment of assignments, achievement, and satisfaction and retention rates in the literature (Hrastinski, 2008). For example, Woods (2002) stated that both quality and quantity of interaction with the instructor and peers are much more crucial to the success of online courses and student satisfaction than to success and satisfaction in traditional courses. Davies and Graff (2005) examined the relationship between the level of online participation and student grades (i.e. high, medium, low, fail). They concluded that students achieving high or medium passing grades engaged more actively than students achieving low passing grades and also students achieving low passing grades were more active than students who failed in the several modules of courses even though greater online interaction did not lead significantly to higher performance.

The nature of online discussion forums offers students the time to reflect on the topic of discussion and thereby encourages a more in depth and constructive dialogue (Garrison, 1997; Johnson 2006). While much of the online or blended delivery of courses in higher education is didactic in nature, the distinctive asynchronous platform can be used to promote peer learning (Harris \& Sandor, 2007; Kear \& Heap, 2007).

\subsection{Importance of participation and interaction in online learning}

The importance of participation and interaction in online learning is extensive in the literature and this cannot be over emphasised. Caspi et al. (2006) mentioned that computer mediated communication (CMC) media such as synchronous or asynchronous tools provided new opportunities for students to participate in online courses, but, participation in the web-based instructional environment tends to be lower while comparing to participation in the face-to-face courses. There are several factors affecting learner participation that was mentioned in online environments. There have still not been enough findings to answer general questions about these factors, especially impact of student characteristics in online discussion due to continuous variations in CMC applications, methods of study, instructions, roles of teachers and students (Prinsen, Volman and Terwel, 2007). As a result, the relationship between participation and interaction and learning outcomes is a complex phenomenon and there is need for more studies related to this phenomenon (Picciano, 2002). This study is a response to more studies agitated for by the Prinsen et al (2007); except that the study did not 
attempt to find relationship between participation and interaction and learning outcomes but rather the participation pattern and it benefits on participants.

Several previous related studies have been conducted. However, most of these studies were conducted especially in Europe, with very few in Africa and none in Nigeria specifically. Zuckerman, Blau and Monroy-Hernandez (2009) investigated participation patterns, users' contributions and gratification mechanisms, as well as the gender differences of Israeli learners in the Scratch online community. The findings showed that: Participation patterns reveal two distinct participation types - "project creators" and "social participators", suggesting different users' needs. Community members gratified "project creators" and "social participators" for their investment - using several forms of community feedback. Gratification at the user level was given both to "project creators" and "social participators" - community members added them as friends. The majority of the variance associated with community feedback was explained by seven predictors. However, gratification at the project level was different for the two participation types - active "project creators" received less feedback on their projects, while active "social participators" received more. Project feedback positively correlated with social participation investment, but negatively correlated with project creation investment. A possible explanation given by the researcher is that community members primarily left feedback to their friends.

Yukselturk (2010) analyzed the factors that affect student participation in discussion forum under the two main purposes. The first purpose was to examine the relationship between the students' individual demographics and categories of students' participation level (inactive, moderate, and active) in discussion forum of an online course. The second purpose was to examine the students' views about reasons for low level of interaction in discussion forum. A total of 196 students who attended computers systems and structures course of online certificate program were included in the study. The data was collected at the beginning and at the end of the course through online survey and semi structured interviews. The descriptive and inferential statistical techniques were used to analyse the quantitative data. The content analysis method was used to analyse the qualitative data. The results of the study indicated that three student characteristics (achievement, gender and weekly hours of Internet use) showed a significant relationship with students' participation level in discussion forum of the online course. Also, the findings emphasized some of the critical issues that should be taken into account in designing online discussions, such as, students' workload and responsibilities, progress of interaction over the Internet taking more time, planned and structured instructional activities in discussion forum.

Similar to Yukselturk study, there are several studies that take interest in factors affecting the participation in online discussion. For example, Godwin, Thorpe and Richardson (2008) mentioned that students taking online courses with a high level of interaction tended to be different from the students taking the courses with a low level of interaction in regard to age, gender and previous qualifications. Although the results were not statistically significant, high interactive students were generally younger, male and having had higher educational qualifications. Balaji (2010) presented a study that contributes to the understanding of the effectiveness of online discussion forum in student learning. A conceptual model based on 'theory of online learning' and 'media richness theory' was proposed and empirically tested. The results show that the perceived richness of online discussion forum has significant positive effect on student participation and interaction, and learning, when used along with traditional classroom lecture. Implications of these findings are discussed as they provide important guidelines for management educators.

Maya and Zuhairi (2009) presented findings of a research on participation in four online learning courses offered by UT Faculty of Economics. The purpose of the study was to have an understanding of how distance students participate and which factors influence participation in online tutorials. Online tutorial has been used by Universities Terbuka (UT) to provide two-way communication channel for distance students, facilitate learning process, and assist them in preparing for examination. The findings of the research indicate that there was low participation of students in online tutorials, in terms of students' contribution to online discussion forum and to work on assignments. Findings of the questionnaire survey indicate that most respondents perceive that tutors have addressed students' questions on topics appropriately and given motivation to students to learn. One constraint in online tutorials relates to slow feedback from tutors to students, while access, costs, and computer skills do not hamper students' participation in online tutorials. Some recommendations are presented. First, tutors are advised to give feedback immediately to respond to students' queries on email.

\subsection{Online discussion forum}

Harris and Sandor (2008) presented a framework of the online discussion forum as a student centred peer earning environment. In particular, the paper presents research findings relating to student views on participation and interaction in these online discussion forums. Data was gathered through semi-structured interviews with students. The findings support the discussed framework because it allows students to take an active role in their learning and enriches their 
learning experience. In summary, the framework provides a viable means of implementing peer learning in an online learning environment. Yang, Li, Tan and Teo (2007) identify the motivational behavioural factors influencing students' intention to participate in an online discussion forum (ODF). Drawing on the literature on social psychology and applying the theory of reasoned action, they develop a conceptual model of intention to participate in an online discussion forum and empirically tested the hypotheses in a cross-sectional quantitative survey. The findings indicate that expectancy on hedonic outcome and utilitarian outcome and peer pressure positively influence the participation intention of students. Also, the perceived importance of learning positively moderates the relationship between utilitarian outcome expectancy and participation intention.

Peachly, Jone and Jones (2006) presented an empirical study involving initiatives that encouraged students to log onto online courses in entrepreneurship delivered by the University of Glamorgan. The aim was to explore items of interest to the online students that may increase participation in the forums and hence potentially enhance engagement with the course module. The findings suggest including online quizzes and games that are relevant to the taught subject can increase the participation levels of the students and possibly enhance the learning process. The findings of this study may inform the design, development and delivery of online learning programmes. The findings also inform strategies of good practice in online moderation and may help to reduce withdrawal rates, which are typically high in the field of elearning.

Coming to Africa, Giannini-Gachago and Seleka (2005) described the experiences gathered in a Masters of Adult Education course at University of Botswana (UB), where 26 students of the University of Botswana and the University of Georgia (UGA) engaged in discussions within the University of Botswana Learning Management System Web CT. Individual participation patterns in the discussions varied widely in this course. Based on variables found in the literature, student participation patterns were analysed - both in terms of quantity (messages read and written) and quality (status of conversational moves and level of critical thinking). Results show that culture or membership of a specific group did not seem to influence participation patterns. Gender was the major influencing variable for participation patterns in terms of both quantity and quality. Other influencing variables were course design, assessment of discussions and the presence of a learning community.

Hodgkinson-Williams and Mostert (2005) proposed an underlying epistemological perspective on informing learning theory of online debating and its potential as a pedagogic strategy to encourage participation in online learning environments. The paper reported student and staff perceptions of an online debate used during a Bed (Hons) course at a South African university. The findings underline the importance of providing explicit procedures to pave the way for students' participation and highlight the potential value of an online debate as a pedagogic strategy to support the development of argumentation and to encourage reflexivity.

In Ghana, Asunka (2008) adopted a qualitative case-study approach to examine the attitudes, experiences, and perceptions of undergraduate students who were enrolled in an online, collaborative learning course at a Ghanaian private university. Data sources included surveys, student and instructor journal entries, email records, individual interviews, and Web-server logs. The study found that the students did not respond favourably to online constructivist teaching approaches such as asynchronous discussions and ill-structured project-based learning activities, and perceived collaborative online learning within their context as a complex, more demanding and time-consuming experience.

As said earlier and as evident from the above previous reviewed studies, studies on the participation of students' in online discussion forum is lacking in the Nigeria universities context. In the light of this, the current study will:

1. Examine the University of llorin undergraduate students' participation in online discussion forum. The specific objectives of the study are:

2. Find out the extent of students' participation in online discussion forum.

3. Determine the benefits of online forum to the students.

4. Investigate the perceived impact of discussion forum on learning performance.

5. Identify the problems or hindrances to students' participation in the online discussion forum.

\section{Research Methodology}

\subsection{Design and Method}

This study adopts a pure quantitative method using survey design approach. This design allows the researcher to drawn on large sample which is representative of the total population (Babbie, 2004). This is to be able to cover a representative population of students at the Faculty of Communication and Information Sciences, University of Ilorin. Moreover, survey approach was chosen because it is the most common approach used in previous related studies (e.g. Virk, 2004; Yang et 
al., 2007). The study commenced in March, 2010 and was completed in May, 2010.

\subsection{Population and Sample}

The population of the study comprised the entire students at the Faculty of Communication and Information Sciences, University of Ilorin, Nigeria. There are five departments in this faculty. These are Computer Science, Library and Information Science, Information Communication Science, Telecommunication Science and Mass Communication. A simple random sampling technique was embarked upon to randomly select 50 students each from the department that have students more than 50 while total enumeration of students was taken in departments with lesser number of students. Only Telecommunication with 10 students and Information Communication Science (ICS) departments with 38students fall into this category and all their students were selected to take part in the study. Eventually, 198 students took part in the study. See (table 1) for the distribution of the students according to departments. The demographic information of the respondents revealed $85(43 \%)$ were female while $113(57 \%)$ were male. Furthermore, the age of the respondents ranged between $19-35$ years with an average age of 27years.

\subsection{Instrument}

A self-designed questionnaire was used for the collection of data on the study. The use of questionnaire for data collection is in line with the quantitative approach used in this study. The design of the questionnaire was informed by the objective and research questions focused in the study. Some items in the questionnaire were designed by the researcher while some others were adapted from various previous related studies (e.g. Virk, 2004, Yang et al. 2007) and modified to suit the purpose of this study. The questionnaire was divided into two sections. Section A requires the respondents' demographic information including gender, department, and age. Section B contained the items. This is sub-divided into parts based on the objectives and research questions. The description of the sub-division goes thus:

Part 1: Pattern of Participation - Four prominent patterns of posting informed by the literature were identified and described for the respondents. They were to respond by indicating which of them best describe their usual posting to the forum.

Part 2: Extent - Here respondents were expected to choose from the option provided e.g. daily, every two days, weekly and fortnightly, and to indicate percentages of posts. Items in this part were adapted from Virk (2004).

Part 3: Benefits - Here respondents were given opportunity to list the benefits they derive from participating in the online discussion forum.

Part 4: Here some items were generated to capture data on the perceived impact of participation in the online discussion forum on learning performance. The response format followed five points Likert scale.

\subsection{Validity and Reliability}

The instrument after its development was given to two experts who have expertise in online discussion research. The suggestions and comments by the experts assisted in the moderation and modification of the items in the instrument. Moreover, construct validity of the instrument used in this study was also conducted. To determine this, a factor analysis was performed using a principal component method of analysis. The results obtained were similar to those obtained by the items of each similar construct of the original instruments where the items were adapted (e.g. Virk, 2004. All loading ranged from good to excellent (Comrey, 1971) thereby authenticates the suitability of the instrument for use in this study. To ensure the reliability of the questionnaire, it was administered on 20 students from a department at the faculty of business and social sciences which did not eventually take part in the study. A test-retest reliability of two weeks interval was conducted and responses collected were subjected to Cronbach alpha. Test re-test is considered relevant because it is the easier method the researcher can use at the time the study. The overall reliability of the questionnaire returned an $r$ $=0.85$ which satisfied the minimum standard of 0.80 suggested for basic research (Wang and Tang, 2003).

\subsection{Procedure of Administration}

The researcher personally administered the questionnaire to the respondents. The fact that the researchers were lecturer in the faculty where the study was conducted enables the easy administration of the questionnaire. The questionnaire was administered in 5 batches with each department constituting a batch. The exercise took three days. Out of 198 copies of questionnaires administered, 195 copies were returned completely filled representing 98.5\% return rate. These 
were used for data analysis on the study.

\section{Interpretation of Results and Data Analysis}

Descriptive statistics including percentages and frequency count together with Friedman Test (for the purpose of ranking items in order of importance) were used for the analysis of data. The results obtained are presented as follows.

Table 1: Demographic Information

\begin{tabular}{|l|c|c|}
\hline Demographics & Frequency & Percentage $\%$ \\
\hline Gender & & \\
\hline Male & 110 & 58 \\
\hline Female & 85 & 42 \\
\hline Total & 195 & 100 \\
\hline Departments & & \\
\hline Computer Science & 50 & 25.6 \\
\hline Lib. and Information Sci. & 50 & 25.6 \\
\hline Mass Communication & 50 & 25.6 \\
Information Comm. Sci. & 35 & 17.9 \\
\hline Telecommunication Sci. & 10 & 5.1 \\
\hline Total & 195 & 100.0 \\
\hline Age & & \\
\hline $\mathbf{1 6}-\mathbf{2 0}$ & 100 & 51.3 \\
\hline $\mathbf{2 1 - 2 5}$ years & 55 & 28.2 \\
\hline $\mathbf{2 6 - 3 0}$ years & 40 & 20.5 \\
\hline Total & $\mathbf{1 9 5}$ & 100.0 \\
\hline
\end{tabular}

The demographic information of respondents who took part in the study in table 1 revealed that $110(56.4 \%)$ were male while $85(43.6 \%)$ were female. This indicates that more male than female took part in the study. Moreover, the demographic information on the respondents' department revealed that 50 respondents each representing (25.6\%) were from the departments of Computer Science, Library and Information and Mass Communication while 35 respondents $(17.9 \%)$ were from department of Communication and Information Science and 10 respondents (5.1\%) were from Telecommunication department. The age distribution of the respondents revealed that $100(51.3 \%)$ fall with the age range of $16-20$ years, $55(28.2 \%)$ were in the age range of $21-25$ years while 40 respondents (20.5\%) fall within the age range of $26-30$ years. It should be noted that the year of study of the respondents ranged from year 2 to 4 (i.e. 200 levels to 400 levels).

Table 2: Pattern of Online Participation

\begin{tabular}{|c|c|c|c|}
\hline $\mathrm{S} / \mathrm{N}$ & Pattern of Online Forum participation & Frequency & Mean Rank \\
\hline 1 & Socratic Questioning & 105 & 8.68 \\
\hline 2 & Reaction Posting & 70 & 8.02 \\
\hline 3 & Sharing personal Opinion/Experiences & 15 & 7.50 \\
\hline 4 & Brainstorming & 5 & 6.38 \\
\hline & Total & 195 & \\
\hline
\end{tabular}

(Chi. Square = 17.36, Df = 9; N = 195; Significant at .001).

To arrive at the results in table 2, respondents were asked to indicate the pattern of their contribution to the forum as describe in the questionnaire. These are Socratic questioning, reaction posting sharing of personal opinion and experiences and brainstorming. The results based on frequency count and Friedman Test conducted reveal clearly that Socratic questioning was the pattern that respondents mostly engaged with $53.8 \%$ and Mean Rank of 8.68 . This was followed by reaction postings (35.0\%, with Mean Rank of 8.02) and sharing of personal opinion and experiences (7.7\% with Mean Rank of 7.50 ) while brainstorming was the least pattern with (2.6\%, with Mean Rank of 6.38$)$. The results also revealed that a significant difference exist between the main and the lowest pattern of online participation by the respondents with (Chi. Square 17.36 at .001 level). Cost of access could be the limiting factor for respondents' 
engagement in brainstorming pattern because the more time spent, the more the payment (Tella and Isah, 2010) while reluctance could be the reason why respondents don't share their opinion and experiences with other course participants. Socratic questioning seeks to get the other person to answer their own questions by making them think and drawing out answers from them. Reaction posting simply means to react to a member's posting. This may take the form of answering a question or commenting on an issue posted by someone. Sharing personal opinions and experiences is intimating the class or the members about one's own experiences while brainstorming is seeking ideas and suggestions of others on a particular issue in addition to one's own understanding of the issue so as to come up with fact or solution.

\subsection{Extent of Participation in the online Forum}

Table 3: Frequency of Participation in Online Discussion Forum

\begin{tabular}{|l|c|c|}
\hline Frequency of Posting & Frequency & Percentage \% \\
\hline Daily & 150 & 76.9 \\
\hline Every Two Days & 30 & 15.4 \\
\hline Weekly & 10 & 5.1 \\
\hline Fortnightly & 4 & 2.1 \\
\hline Monthly & 2 & 0.5 \\
\hline Total & 195 & 100 \\
\hline
\end{tabular}

Table 3 show the depth of the respondents' participation in the online discussion forum. The result reveals that a considerable number of respondents $150(76.9 \%)$ post comments and contribution on a daily basis. This is followed by 30 $(15.4 \%)$ who indicated they make posting on every two days. Moreover, 10 respondents (5.1\%) post comments and contribution on weekly basis while a limited percentage $(2.1 \%$ and $0.5 \%)$ do make their own posting every fortnight and monthly. That larger percentage of respondents make posting to the forum daily and on every two days; show that the respondents are deeply involved in the online forum.

To further examine extent of respondents' participation in the online forum, they were asked the percentage of posts they read but do not respond as informed by Virk (2004). The answer is presented in table 4.

Table 4: Percentage of Read but no Response Posts

\begin{tabular}{|c|c|c|}
\hline Read but no Response Posts in \% & Frequency & Percentage \% \\
\hline $20 \%$ & 160 & 82.05 \\
\hline $40 \%$ & 25 & 12.8 \\
\hline $60 \%$ & 4 & 2.1 \\
\hline $80 \%$ & 4 & 2.1 \\
\hline $90 \%$ & 2 & 1.0 \\
\hline Total & 195 & 100 \\
\hline
\end{tabular}

Table 4 shows the percentage of post read but not responded to by the respondents. The result reveals that 160 $(82.05 \%)$ read as lower as $20 \%$ of the post but don't have opportunity to respond. Moreover, the respondents were asked to indicate the percentage they read and respond to according to (Virk, 2004). The result is presented in table 5.

Table 5: Percentage of Read and Response Posts $N=195$

\begin{tabular}{|c|c|c|}
\hline Read and Respond Posts in \% & Frequency & Percentage $\%$ \\
\hline $80 \%$ & 158 & 81.0 \\
\hline $60 \%$ & 20 & 10.3 \\
\hline $90 \%$ & 15 & 7.7 \\
\hline $40 \%$ & 2 & 1.0 \\
\hline $20 \%$ & - & - \\
\hline Total & $\mathbf{1 9 5}$ & $\mathbf{1 0 0}$ \\
\hline
\end{tabular}

Table 5 reveals the percentage of posts read and responded to by the respondents. The result showed that $158(81 \%)$ usually read and respond to all posts on the forum. If this is added to $10.3 \%$ and $7.7 \%$ that imaging reading and posting 
contribution up to $60 \%$ and $90 \%$ respectively, the results suggest that a considerable percentage of the respondents are making use of the forum. Looking at this result with that in table 5 , it is clear that to a great extent respondents in this study were fully and deeply involved taken part in the online form.

\subsection{Benefits of online Forum}

Table 6: Benefits of Participation in Online Forum N =195

\begin{tabular}{|c|l|c|c|}
\hline S/N & \multicolumn{1}{|c|}{ Benefits } & \multicolumn{1}{|c|}{ Freq. } & Mean Rank \\
\hline 1. & Encourages intellectual support (sharing of knowledge and ideas) between participants. & 195 & 9.63 \\
\hline 2. & Enables introvert to freely air and express their own opinion. & 194 & 9.45 \\
\hline 3. & $\begin{array}{l}\text { Increased students' participation in teaching and learning than what obtain in a face-to-face } \\
\text { instructional setting. }\end{array}$ & 194 & 9.45 \\
\hline 4. & Promote social interaction between course participants & 193 & 8.67 \\
\hline 5. & Provide opportunity to freely ask colleagues what is not clear & 192 & 8.43 \\
\hline 7. & Motivation to become more involved with the course content. & 190 & 7.66 \\
\hline
\end{tabular}

On the benefits of participating in the online forum, the result based on frequency count and Friedman Test conducted reveals seven most prominent benefits in the following order. Encouraging intellectual support in terms of sharing of ideas (100\%, Mean Rank of 9.63), introvert free expression of opinion (99.5\%, Mean Rank of 9.45), students participate more than in a face to face class (99.5\%, Mean Rank of 9.45), promotion of social interaction 98.9\%, Mean Rank of 8.67), opportunity of asking colleagues what is not clear (98.5\%, Mean Rank of 8.43), provide motivation to be involved with the course content (97.4\%, Mean Rank of 7.66). Asides of the items provided for the respondents to respond to, other benefits identified by the respondents as they were asked to specified others are: Interactions with other students in the online discussion forums challenge me to critically reflect on the discussion topics, interactions with other students in the online discussion forums encourage me to continue participating in the discussion forums and interactions with other students in the online discussion forums encourage me to be more active in the discussion forums in terms of writing more and/or longer postings. The results further indicate that all the benefits identified by the respondents are significant with (Chi-Square 20.66, Df. 9 and at .001 level).

Table 7: Perceived Impact of Discussion Forum on Student learning and Performance N =195

\begin{tabular}{|c|l|c|c|c|c|c|}
\hline S/N & \multicolumn{1}{|c|}{ Items } & SA & A & N & D & SD \\
\hline 1 & I believe that participating in the forum would help my learning & $\begin{array}{c}105 \\
(53.8)\end{array}$ & $\begin{array}{c}70 \\
(35.8)\end{array}$ & $\begin{array}{c}5 \\
(2.5)\end{array}$ & $\begin{array}{c}9 \\
(4.6)\end{array}$ & $\begin{array}{c}6 \\
(3.0)\end{array}$ \\
\hline 2 & $\begin{array}{l}\text { Using discussion forum as supplementary to face to face teaching } \\
\text { has improved my learning performance. }\end{array}$ & $\begin{array}{c}115 \\
(58.9)\end{array}$ & $\begin{array}{c}53 \\
(27.1)\end{array}$ & $\begin{array}{c}10 \\
(5.0)\end{array}$ & $\begin{array}{c}10 \\
(5.0)\end{array}$ & $\begin{array}{c}7 \\
(3.5)\end{array}$ \\
\hline 3. & $\begin{array}{l}\text { Receiving and responding to other peoples' posting is increasing my } \\
\text { reasoning and retention ability }\end{array}$ & $\begin{array}{c}121 \\
(62.1)\end{array}$ & $\begin{array}{c}48 \\
(24.6)\end{array}$ & $\begin{array}{c}16 \\
(8.2)\end{array}$ & $\begin{array}{c}6 \\
(3.0)\end{array}$ & $\begin{array}{c}4 \\
(2.1)\end{array}$ \\
\hline 4. & $\begin{array}{l}\text { Contributing to the brainstorming and other activities on the forum is } \\
\text { deepening my knowledge of the courses. }\end{array}$ & $\begin{array}{c}117 \\
(60)\end{array}$ & $\begin{array}{c}57 \\
(29.2)\end{array}$ & $\begin{array}{c}6 \\
(3.0)\end{array}$ & $\begin{array}{c}8 \\
(4.2)\end{array}$ & $\begin{array}{c}7 \\
(3.5)\end{array}$ \\
\hline \multirow{2}{*}{5.} & $\begin{array}{l}\text { Overall, discussion forum has contributed a lot to the improvement of } \\
\text { my GPA and general performance in all the courses. }\end{array}$ & $\begin{array}{c}125 \\
(64.1)\end{array}$ & $\begin{array}{c}57 \\
(29.2)\end{array}$ & $\begin{array}{c}3 \\
(1.5)\end{array}$ & $\begin{array}{c}5 \\
(2.5)\end{array}$ & $\begin{array}{c}5 \\
(2.5)\end{array}$ \\
\hline
\end{tabular}

Table 7 reveals results on the perceived impact of participating in the discussion forum on the respondents learning performance. Using percentages and frequency count, the results indicated that (89.6\%) strongly and agree that participating in the forum would help their learning. On the other hand, $(7.6 \%)$ disagree and strongly disagreed while $(2.5 \%)$ were neutral. Furthermore, the results indicated that (86\%) strongly and agree that participating in the forum has improved my learning performance. On the other hand, (8.5\%) disagree and strongly disagreed while (5\%) were neutral. Additionally, the result revealed that (86.7\%) indicate responding to other peoples' posting is increasing their reasoning and retention ability while (5.1\%) disagree and strongly disagreed. So also, (89.2\%) submitted that contributing to the brainstorming and other activities on the forum is deepening their knowledge of the courses; (7.7\%) disagree and strongly disagreed while (3.0\%) were neutral. Finally, (93.3\%) submitted that overall, discussion forum has contributed immensely to the improvement of their GPA and general performance in all the courses. These results summarily indicate that 
majority of the respondents on this study perceived that participating in the online discussion has really contributed to their learning performance and which has eventually increased their GPA.

\subsection{Problems of Online Forum}

Table 8: Problems of Participation in Online Forum N =195

\begin{tabular}{|c|l|c|c|}
\hline S/N & \multicolumn{1}{|c|}{ Problems } & Freq. & Mean Rank \\
\hline 1 & Incessant Power outage & 193 & 8.78 \\
\hline 2 & Time factor based on tight schedule & 178 & 8.16 \\
\hline 3 & Limited access to computers and Internet on campus & 170 & 7.90 \\
\hline 4 & Cost of Access & 167 & 7.67 \\
\hline 5 & Participants become "unruly" if anonymous (e.g. excessive joking) & 154 & 6.62 \\
\hline 6 & Slow connectivity & 150 & 6.38 \\
\hline 7 & Inadequate knowledge and skills to use the Internet. & 143 & 5.02 \\
\hline
\end{tabular}

Note - Respondents did not specify any other problems apart from the ones in the questionnaire.

Table 8 reveals the problems and hindrances to the respondents' participation in the online forum. The results showed the issue of incessant power outage as the most prominent problem. This was indicated by $(98.9 \%$, with a Mean Rank of 8.78) of the respondents. Following this immediately is the problem of time factor indicated by (91.3\%, with a Mean Rank of 8.16$)$, the respondents (85.6\%, with a Mean Rank of 7.90) indicated limited access to computers and Internet on campus which results to many students using cyber cafe. Furthermore, cost of access to computers and the Internet was indicated by (79\% with a Mean Rank of 7.67) Findings also indicated that some respondents usually become unruly in terms of posting excessive joking and flaming with (76.9\% and with a Mean Rank of 6.38$)$, while inadequate knowledge and skills to use the Internet (73.3\% and Mean Rank of 5.02). Aside of the problems included in the table, other problems identified by the respondents were: difficulty in enhancing social interaction based on the fact that most people are doing the discussion forums because of the assessment requirements.

\section{Discussion of Findings}

This study has established the undergraduates' participation in the online discussion forum in terms of pattern, frequency and extent of participation, perceived impact of participation on learning and problems encounter in the process of participation. Through data collection and analysis; the four research questions developed have been answered. The finding that Socratic questioning, sharing of personal opinion, reaction posting and brainstorming are the major pattern of participation demonstrated by the respondents in this study correspond with the earlier findings (e.g. Zuckerman, Blau and Monroy-Hernandez, 2009) who investigated participation patterns, users' contributions and gratification mechanisms with the reported that: (1) Participation patterns reveal two distinct participation types "project creators" (participants who create thought for discussion by members) and "social participators" ( those who share their experience with others). Though the pattern established by these two studies differs considerably. However, one thing that is pertinent is that there are types or patterns of participation in the online discussion forum and this has been confirmed in this study.

The finding that reveals a great extent of participation in the online forum with the majority making postings on a daily basis is in consonant with the report by Peachly et al (2006). Participant in this study attracted $54 \%$ of the total postings to the online forum. The great extent of participation revealed in this study may be due to the factors identified such as perceived contribution to respondents learning and peer pressure identified by Yang et al (2007). Similarly, the perceived importance of learning and utilitarian outcome expectancy and participation intention may also be other responsible factors. In addition, the major reasons summed up as "generally getting used to something new, encouragement from instructor and understanding how important discussions were for learning" identified by (Lorraine, 2004) also lend credence to this current finding. Still on the extent of participation, the report by Virk (2004) that majority of the students read somewhere between 70 to 80 percent of the posts; while the range of posts that were read but not responded to was wider, 40 to 90 percent also support or confirm the present finding. Reasons stated for not responding to the posts was not having time to respond. This also corroborates the current findings relating to number of post read but not responded revealed in this study. Conversely, Maya and Zuhairi (2009) findings that there was low participation of students in online tutorials, in terms of students' contribution contradict the present finding of this study. This variation may be due to the platform used for the discussion forum. 
This study identified some of the benefits derived by the participant in their participation in the forum as encouragement of intellectual support in terms of sharing of knowledge and ideas between participants, introvert free expression of opinion, students participate more than in a face to face class, promotion of social interaction, opportunity of asking colleagues what is not clear and others as the most common benefits. The result is in agreement with the finding by Peachy et al (2006) who indicated that online discussion that are relevant to the taught subject can increase the participation levels of the students and possibly enhance the learning process. Similarly, Balaji (2010) report online discussion forum has significant positive effect on students' participation and interaction, and learning, when used along with traditional classroom lecture; together with the report by Picciano (2002) who found that students perceived greater quality and quantity of learning as a result of participating in the discussions forum confirm the benefits of online discussion forum identified in this study.

Just like the previous related studies, the current study also revealed some identifiable problems encountered by the participants in the online forum. These are incessant power outage and time factor based on tight schedule, limited access to computers and Internet, cost of access to computers and the Internet, participants becoming unruly in terms of posting excessive joking and flaming, inadequate knowledge and skills to use the Internet and others. This result correspond with Maya and Zuhairi (2009) who indicated the constraint in online tutorials relates to slow feedback from tutors to students, access, costs, and computer skills. Contrarily, Vonderwell and Zachariah (2005) revealed technology and interface characteristics, content area experience, student roles and instructional tasks, and information overload while Vrasidas and Mclsaac (1999) who examined the nature of interaction in an online course from both teacher and student perspectives; concluded that the structure of course, class size, feedback, and prior knowledge of computer mediated communication all affected the interaction in the online forum. This confirms the fact that there are problems associated with online discussion forum irrespective of who, where, when, what and the nature of the contribution.

\section{Conclusion}

So far the study has examined the undergraduates' participation in the online discussion forum in terms of pattern, frequency and extent of participation, perceived impact of participation on learning and problems encounter in the process of participation. The results have indicated that majority of the respondents are participating in the online forum and they dully committed to it. Four prominent pattern of participation were identified by the respondents. These are Socratic questioning, sharing of personal opinion and experiences, reaction posting and brainstorming. Furthermore, the study revealed a great extent of participation in the online forum with the majority making postings on a daily basis. Similarly, considerable number of respondents usually read and responds to all posts received. The results confirm encouragement of intellectual support in terms of sharing of knowledge and ideas between participants and others as the most common benefits. Incessant power outage and time factor based on tight schedule and others were identified as the problems participants encounter in the online forum.

\section{Limitations}

This study has assessed the undergraduates' participation in the discussion forum. However, like many other research, this study has certain limitations. For instance, the sample used was selected from just one university out of many universities in Nigeria. Hence one cannot generalize the findings to other populations such as universities, colleges of education and polytechnics students

The study focused only the students' participation ignoring the tutors' participation which is very important. It should be noted that tutors are moderator of the forum. Therefore, knowing their participation pattern and the other roles they play could be significant.

The study only report the impact of the discussion forum on the respondents' learning based on the perception of the respondents. In the real sense, comparison of the participation pattern with their GPA could have been the best. Future researchers are therefore called upon to focus on these limitations and work out how they can be minimized so as to improve the generalizability of the findings.

\section{Recommendations}

There is need for more success story in the online discussion forum at the Faculty of Communication and Information Science, University of llorin. This is to say that increase participation in terms of creating online forum for all courses in the faculty with the lecturer playing their effectively as facilitators. For this to happen there is need for the students to be 
effective communicator. The use and practice of chat, email, feedback on assignments, sharing examples and instant messaging as put forward by (Beck and Greive, 2005) can help in this direction.

It should be noted that online discussion forum is very porous as anyone can post $X$ number of times. However, insightful, relevant comments or questions that stimulate critical thinking and active exploration of course material usually impact learning. In view of this, students are called upon to contribute meaningfully to the forum as this can go a long way to enhance their performance

The study has revealed the pattern of students' participation in the online forum in term of the frequency of use and the rest. In the light of this, there is need for more students' motivation on the part of the lecturers. This will enables students who have not been fully involved in it to do so. This they can do by making sure that they are providing immediate feedback on students' postings and clarifications. Moreover, they can also make use of token reinforcement such as 'good posting' 'brilliant idea' 'fantastic contribution', etc. These can motivate them to increase their participation.

In order to improve students' participation in the online forum, the University authority should provide enough free internet facilities outlets within the university community just as it is done in developed countries.

This study might serves to be the first of its kind in Nigeria as far as the use of online discussion forum is concern to facilitate and deepened students' knowledge in a course. In the light of this, other universities in Nigeria, Africa and outside Africa should consider the use of online forum in the teaching of their course considering the benefits indicated associated with it in this study.

\section{Suggestions for Further Studies}

Future researchers may consider looking into the area of factors promoting students participation in the online forum in the Nigeria context.

The role played by lecturers and their impact in terms of facilitating and promoting effective participation on the part of the learners could also be look into.

\section{References}

Asunka, S. (2008). Online Learning in Higher Education in Sub-Saharan Africa: Ghanaian University students' experiences and perceptions. International Review of Research in Open and Distance Learning 9 (3), 1-23.

Balaji, M.S. \& Chakrabarti, D. (2010). Student Interactions in Online Discussion Forum: Empirical Research from 'Media Richness Theory' Perspective. Journal of Interactive online Learning, Vol. 9 No.1, pp. 1-21.

Babbie, E. (2004). The Practice of Social Research (10th Ed.). Belmont, CA: Thomson/Wadsworth.

Beck, E. \& Greive, D. (2005). Going the distance: A handbook for part-time \& adjunct Faculty who teach online. Ann Arbor, MI: Adjunct Advocate, Inc.

Blau, I; Mor, N; \& Neuthal, T. (2009). Open the Windows of Communication: Promoting Interpersonal and Group Interactions Using Blogs in Higher Education", Interdisciplinary Journal of E-Learning and Learning Objects 5, 233-246.

Brady, L. (2004). The role of interactivity on the effectiveness of an educational science website for middle school students. Unpublished Dissertation. Wichita State University.

Caspi, A., Chajut, E., Saporta, K., \& Beyth-Marom, R. (2006). The influence of personality on social participation in learning environments. Learning and Individual Differences 16 (2), 129-144.

Cheong, W.S. \& Hew, K.F. (2008). Attracting student participation in asynchronous online discussions: A case study of peer facilitation. Computers and Education 51 (3), .1111- 1124.

Comrey, A. L. (1971). An introduction to factor analysis. New York: Academic Press.

Davies, J. \& Graff, M. (2005). Performance in e-learning: online participation and student grades. British Journal of Educational Technology 36 (4), 657-664.

Garrison, D. R. (1997). Computer conferencing: the post-industrial age of distance education", Open Learning: The Journal of Open and Distance Learning 12 (2), 3-11.

Giannini-Gachago, D. \& Seleka, G. (2005). Experiences with international online discussions: Participation patterns of Botswana and American students in an Adult Education and Development course at the University of Botswana. International Journal of Education and Development using Information and Communication Technology (IJEDICT) 1 (2), 163-184.

Godwin, S. J., Thorpe M. S., \& Richardson, J. T. E. (2008). The impact of computer- mediated interaction on distance learning", British Journal of Educational Technology, Vol. 39 (1), $52-70$.

Johnson, G. M. (2006). Synchronous and asynchronous text-based CMC in educational contexts: a review of recent research. TechTrends 50 (4), 46-53.

Harris, N \& Sandor, M. (2008). Student views on participation and interaction in student centred online discussion forums. ASCLITE, Melbourne, Australia.

Harris, N. \& Sandor, M. (2007). Developing online discussion forums as student centred peer e-learning environments. In ICT: Providing 
choices for learners and learning. Proceedings ASCILITES Singapore 2007. Retrieved 17 May, 2011, from http://www.ascilite.org.au/conferences/singapore07/procs/harris.pdf

Ho, S. (2002). Evaluating students' participation in on-line discussions. Retrieved 17 May, 2011, from: http://ausweb.scu.edu.au/aw02/papers/refereed/ho/paper.html

Hodgkinson-Williams, C. \& Mostert, M. (2005). Online debating to encourage student participation in online learning environments: A qualitative case study at a South African university. International Journal of Education and Development using Information and Communication Technology (IJEDICT) 1 (2), 94-104.

Hrastinski, S. (2008). What is online learner participation? A literature review", Computers \& Education 51 (4), 1755-1765.

Kear, K. L. \& Heap, N. W. (2007). Sorting the wheat from the chaff: investigating overload in educational discussion systems. Journal of Computer Assisted Learning 23 (3), 235- 247.

Laurillard, D. (1993). Rethinking university teaching. Routledge, London.

Maya, M.B. \& Zuhairi, A. (2009). Students' participation in online learning in business courses at University Terbuka, Indonesia. Retrieved 18 May, 2011, from http://www.ou.nl/Docs/Campagnes/ICDE2009/Papers/Final_paper_054mayamaria.pd

Peachey, P; Jones, P \&. Jones, A. (2006). Encouraging Student Participation in an Online Course Using 'Pull' Initiatives. Electronic Journal of E-learning EJEL. Retrieved 17 May, 2011, from http://www.ejel.org/volume-4/v4-i1/peachey-paul-et-al.pdf

Picciano, A. G. (2002). Beyond student perceptions: Issues of interaction, presence, and performance in an online course. Journal of Asynchronous Learning Networks 6 (1), 2140.

Prinsen, F., Volman, M. L. L., \& Terwel, J. (2007). The influence of learner characteristics on degree and type of participation in a CSCL environment", British Journal of Educational Technology 38 (6), 1037-1055.

Rafaeli, S., \& Ariel, Y. (2008). Online motivational factors: Incentives for participation and contribution in Wikipedia", In A. Barak (Ed.), Psychological aspects of cyberspace: Theory, research, applications. Cambridge University Press.

Roblyer M.D. \& Ekhaml, L. (2000). How interactive are your distance courses? A rubric for assessing interaction in distance learning. Online Journal of Distance Learning Administration, Vol. 3, No. 2. Retrieved May 5, 2004, from http://www.westga.edu/ distance/roblyer32.html

Rovai, A. P., \& Barnum, K. T. (2003). On-line course effectiveness: An analysis of student interactions and perceptions of learning. Journal of Distance Education 18 (1), 57- 73.

Virk, B. (2004). A Balancing Act: Improving Student Online Discussion Participation. Retrieved 17 May, 2011, from http://itdl.org/journal/jun_04/index.htm

Vonderwell, S., \& Zachariah, S. (2005). Factors that influence participation in online learning", Journal of Research on Technology in Education 38 (2), 213-230.

Vrasidas, C., \& Mclsaac, M. (1999). Factors influencing interaction in an online course. The American Journal of Distance Education 13 (3), 22-36.

Wang, S. \& Tang, T. I. (2003). Assessing customer perceptions of Web sites service quality in digital marketing environments. Journal of End User Computing 15 (.3), .14-31.

Wishart, C., \& Guy, R. 2009. Analysing responses, moves, and roles in online discussions. Interdisciplinary Journal of E-Learning and Learning Objects 5, 129-144. Retrieved 18 May, 2011, from http:/lijello.org/Volume5/IJELLOv5p129-144Wishart658.pdf

Yang, X; Li, Y; Tan, C.H, \& Teo, H.H. 2007. Students' participation intention in an online discussion forum: Why is computer-mediated interaction attractive? Information and Management 44 (5), 456 - 466.

Yukselturk, E. 2010. An investigation into the factors affecting students' participation level in an online discussion forum", The Turkish Online Journal of Educational Technology 9 (2), 24-32

Zuckerman, O; Blau, I. \&Monroy-Hernández, A. 2009. Children's Participation Patterns in Online Communities: An Analysis of Israeli Learners in the Scratch Online Community", Interdisciplinary Journal of E-Learning and Learning Objects. 5, 263- 274. 


\section{Wake-Up.}

A Health Promotion Project for Sub-Saharan University Students:

Results of Focus group sessions

Jesca Mercy Batidzirai', G Anita Heeren², C Show Marange ${ }^{3}$, Arnold Rumosa Gwaze ${ }^{3}$, Andrew Mandeya ${ }^{3}$, Zolani Ngwane $^{4}$, John B Jemmott III2, Joanne C Tyler ${ }^{3}$

${ }^{1}$ School of Mathematics, Statistics and Computer Science, University of KwaZulu-Natal, Private Bag X01, Scottsville, 3209, Pietermaritzburg, South Africa,

${ }^{2}$ Department of Psychiatry, Department of Communication and Health Behavior, Perelman School of Medicine, University of Pennsylvania, Market Street 3535, Suite 520, Philadelphia PA 19104, USA

${ }^{3}$ Department of Biostatistics, University of Fort Hare, Private Bag X1314, Alice, South Africa

4Department of Anthropology, Haverford College, Lancaster Road, Haverford PA 19030, USA

Corresponding author address: e-mail: jesbats@gmail.com 